\title{
Automated displacement measurements on historical canvases
}

\author{
Fausto Del Sette ${ }^{1 *}$ (D), Fabrizio Patané 2 , Stefano Rossi ${ }^{3}$, Mauro Torre ${ }^{4}$ and Paolo Cappa ${ }^{1 \wedge}$
}

\begin{abstract}
Background: In this paper we describe a configurable system based on laser displacement sensors for the contactless acquisition of 3D and 2D shapes of near-planar objects such as the paintings.

Methods: The system is based on two single-point laser triangulation sensors, a planar robot and a suite of software for driving the sensors, acquiring and post-processing the collected data. As a demonstration of the developed system we monitored three artifacts with the different aims to monitor the elastic properties of the artworks and the effectiveness of support frames in compensating the micro-climate fluctuations: the "Annunciazione" Antonello da Messina, the "Paliotto di San Domenico", and the "Portiera Oddi-Montesperelli".

Results: In the "Annunciazione" case, the canvas response to tensioning trials was analyzed. The collected data permitted to quantify a maximum displacement of 0.9 and $1.5 \mathrm{~mm}$ for the tensioning tests at 1 and $2 \mathrm{~mm}$, respectively. In the "Portiera" case, the displacement difference between the left and right canvas sides was $(1.0 \pm 0.13) \%$, due to the inherent anisotropy of the material and by the structure of the artifact. In the "Paliotto" case, instead, minor displacement variations of the gilt leather due to the environment were observed, due to the analysis conducted prior of the restoration.
\end{abstract}

Conclusions: The overall obtained results demonstrated that the system is able to provide useful data for the art conservation field, with a max inaccuracy less than $100 \mu \mathrm{m}$.

Keywords: Antonello Da Messina, Contactless measurement, Masterpieces, Laser, Automation-robotics

\section{Background}

Cultural heritage constitutes a fundamental resource, even in economic terms, so restoration becomes an essential step towards the conservation, and therefore valorization of artistic artworks. In order to preserve them, institutions need to control the environmental parameters, and to plan periodical inspections of numerous masterpieces.

Focusing the study on canvas paintings and gilt leather handworks, the problems are typically represented by rheological processes and chemical deteriorations due to the action of bacteria and mildews [1]. The necessity to define non-invasive tests for the rheological analysis, i.e., the displacement vs. fiber tension, is strictly related to the

\footnotetext{
*Correspondence: fausto.delsette@uniroma1.it

$\wedge$ Deceased

1 Department of Mechanical and Aerospace Engineering, DIMA, Sapienza University of Roma, via Eudossiana, Rome, Italy

Full list of author information is available at the end of the article
}

methodology of canvas production. The most common solution for producing flat, light, easy to transport, and resistant canvas consists in stretching woven fibers on a frame [2]. Therefore, the elasticity characteristics of the support system is the basis for the adhesion of the color film on the canvas [3]. Tensile stress tests performed on canvas painting showed that the relative humidity $(\mathrm{RH})$ of the environment is the main parameter influencing the tension variation of the fibers [4]. The RH monitoring in the exhibition environment can prevent the onset of cracks in the painting film especially in case the elastic properties of the canvas are degraded due to the aging [5, 6]. The daily monitoring of the environmental parameters has also to be supported by periodic structural diagnoses, in order to control the mechanical characteristics of the canvas fiber and the progress of the cracks [7]. The need of inspecting historical paintings without affecting them, led to develop nondestructive methods of investigation; 
laser sensors are among the main used devices in the artworks conservation $[8,9]$. Currently, a lot of non-invasive diagnostic techniques are used depending on the material constituting the artworks: interferometry, shearography and holography for displacement monitoring [10-13]; and, X-ray laminography for density and internal crack analysis [14].

Specifically regarding the 3D scanning devices, in the field of 3D digitalization of canvas paintings, the quantity and precision of information provided by those systems seems to be exorbitant due to near-planarity characteristic of canvas. However, the acquisition of surface shape and color digitalization gained recently attention in cultural heritage. For example, Elkhuizen et al. [15] simultaneously captured color and topography of paintings and reproduced them via a fringe projection and stereo imaging system. Zaman et al. [16] proposed a novel method based on two cameras and a projector for a 3D topography analysis and a subsequent 3D reproduction. Karaszewski et al. [17] developed a system based on a 3D structured light head moved via linear positioners to precisely measure the shape and the color in the perspective also to eliminate the art forgery problem.

There are several products available on the market, suitable for almost any type of application. The main features that distinguish one system from another are accuracy and resolution, scanning size, and apparatus cost. The cost, for a professional scanner and the associated reconstruction software, starts from about $20.000 €$, and the accuracy is variable, from $10 \mu \mathrm{m}$ to $1 \mathrm{~mm}$. Other important factors are the transportability, the ability to work with different surfaces, the maneuverability, and the speed of the scanning system, etc.

The literature reports different interesting systems, which have been used for the scan of canvas paintings.

The Lucida 3D (Factum Foundation) is a laser scanner, mounted on a xy cartesian robot, with a resolution of $100 \mu \mathrm{m}$, and a maximum depth of field of $25 \mathrm{~mm}$; the maximum scan area is $480 \times 480 \mathrm{~mm}^{2}$. The system was used to analyze the "The Triumph of the Church" of P. P. Rubens (Museo del Prado in Madrid) [18]. The device developed by the National Research Council of Canada is a $3 \mathrm{D}$ laser scanner with a tracking system for large surface reconstruction, with a spatial resolution (X and $\mathrm{Y}$ ) of $50 \mu \mathrm{m}$, and a maximum depth uncertainty of $10 \mu \mathrm{m}$, capable to acquire also the color. The system was used to analyze the "Mona Lisa" of L. Da Vinci, and the "Femme Nue Dans un Paysage" of A. Renoire [19-21]. The smartSCAN (Aicon) is a structured light scanner with a spatial resolution (X and $\mathrm{Y}$ ) of $100 \mu \mathrm{m}$, and a measuring depth of $150 \mathrm{~mm}$. The system was used to analyze a collection of painting placed in the "Pepoli-Capogrande Palace" (Bologna, Italy) [22]. That device can reach a lateral resolution of $60 \mu \mathrm{m}$ and a feature accuracy of $15 \mu \mathrm{m}$, with a special focus on heritage studies [23].

Considering the classification of the laser devices in the field of conservation science reported by Pezzati [24], our apparatus is at triangulation laser system based on singlepoint-projection [25], whereas the most of the reported systems are generally based on surface or line detection, our laser sensor is based on single point measurement. Specifically, here we plan to scan the surface of historical canvas paintings by means of a triangulation laser sensor mobilized via an XY robot. The apparatus allows to perform the scanning of a generic surface with medium accuracy (inaccuracy $< \pm 50 \mu \mathrm{m}$ ). The resolution is obtained at a relatively low cost, but with a slow scanning speed, and it is mainly determined by the spatial reproducibility of the positioning system.

As a benchmark for the system, we acquired the canvas shapes of three historical artifacts, during their restoration phase at the ISCR institute. The first artifact was a canvas painting masterpiece ("Annunciazione", Antonello da Messina), which was subjected to tensioning test by the institute technical personnel. The second and the third artifacts were two gilt leather canvas ("Paliotto di San Domenico" and "Portiera Oddi-Montesperelli"), which were under study in order to estimate the effect of temperature and $\mathrm{RH}$ on the canvas fibers.

\section{Masterpieces}

In order to test the performances of the proposed system, an experimental analysis was carried out on three ancient artifacts that were under restoration at the Istituto Superiore per la Conservazione ed il Restauro (ISCR Roma, Italy). They are part of a conservation and restoration project focused on acquiring information on the state of conservation of the paintings, as well as on the longrange development of novel frames capable to compensate the effects induced by environmental temperature and humidity fluctuations.

The first painting was the "Annunciazione" by Antonello da Messina $\left(1474,1.80 \times 1.80 \mathrm{~m}^{2}\right)$, which is a part of the permanent collection at the Galleria Regionale Palazzo Bellomo (Siracusa, Italy). In 1907, the painting was transferred on double canvas due the deterioration of the wood support causing numerous crackles on the image Fig. 1. The cracks are the main reason of separation between the color film and the canvas, and canvas displacements induced by microclimate effects can amplify the deterioration.

Secondly, we investigated two furnishings, made with the technique of gilt and painted leather. The "Portiera Oddi Montesperelli", is a sixtennth century door hanging-measuring $1.76 \times 1.08 \mathrm{~m}^{2}$-from the Museo e Galleria Mozzi Bardini (Firenze, Italy) presently exposed in 


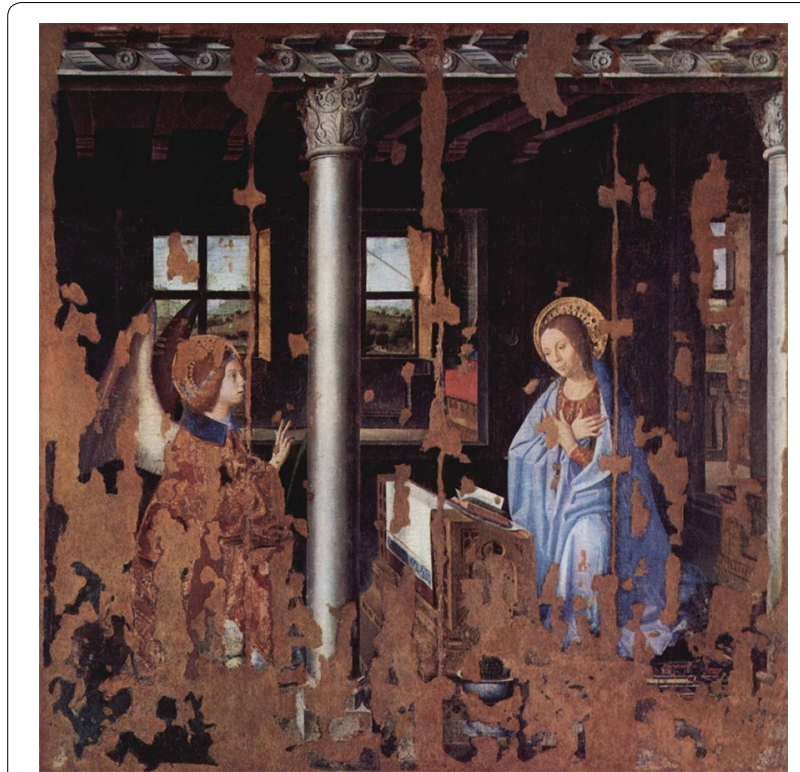

Fig. 1 "Annunciazione-Antonello da Messina"

the Medicean Villa (Cerreto Guidi, Italy) Fig. 2. The "Paliotto di San Domenico", is a seventeenth century "Antependium", belonging to the Museo dell'Opera del Duomo in Orvieto (Terni, Italy), composed by eleven squared skins sewn together for a total surface of $0.97 \times 2.14 \mathrm{~m}^{2}$ Fig. 3.

\section{Experimental methods}

The system we have designed is contactless, capable of scanning shapes of about $1.40 \times 0.90 \mathrm{~m}^{2}$, and able to be configured and set up for any situation, thanks by the Cartesian robots used for the lasers scansion. Among the $3 \mathrm{D}$ imaging sensors $[26,27]$ we decided to use the single point laser triangulation methodology due to: (i) the high accuracy in a given field of view, (ii) the inherent insensitivity to the environmental illumination conditions, and (iii) the high acquisition rate [28].

Taking into account the irreplaceable nature of the pieces and the potentially damage caused by the laser beam and the induced heat, an overriding concern was to avoid harming the masterpieces. Therefore, being required that the system operated at the highest safety level, we choose a red semiconductor laser with a power of $0.5 \mathrm{~W}$ and it is moved continuously during scanning.

The acquisition system was composed of: (i) two laser displacement-sensors (PM Instruments, LDS, FSO $30 \mathrm{~mm}, 0.01 \%$ ), and (ii) a two-axes XY-robot (Robostar, ROK stroke $300 \mathrm{~mm}$, payload $40 \mathrm{~kg}$ ) for the sensor
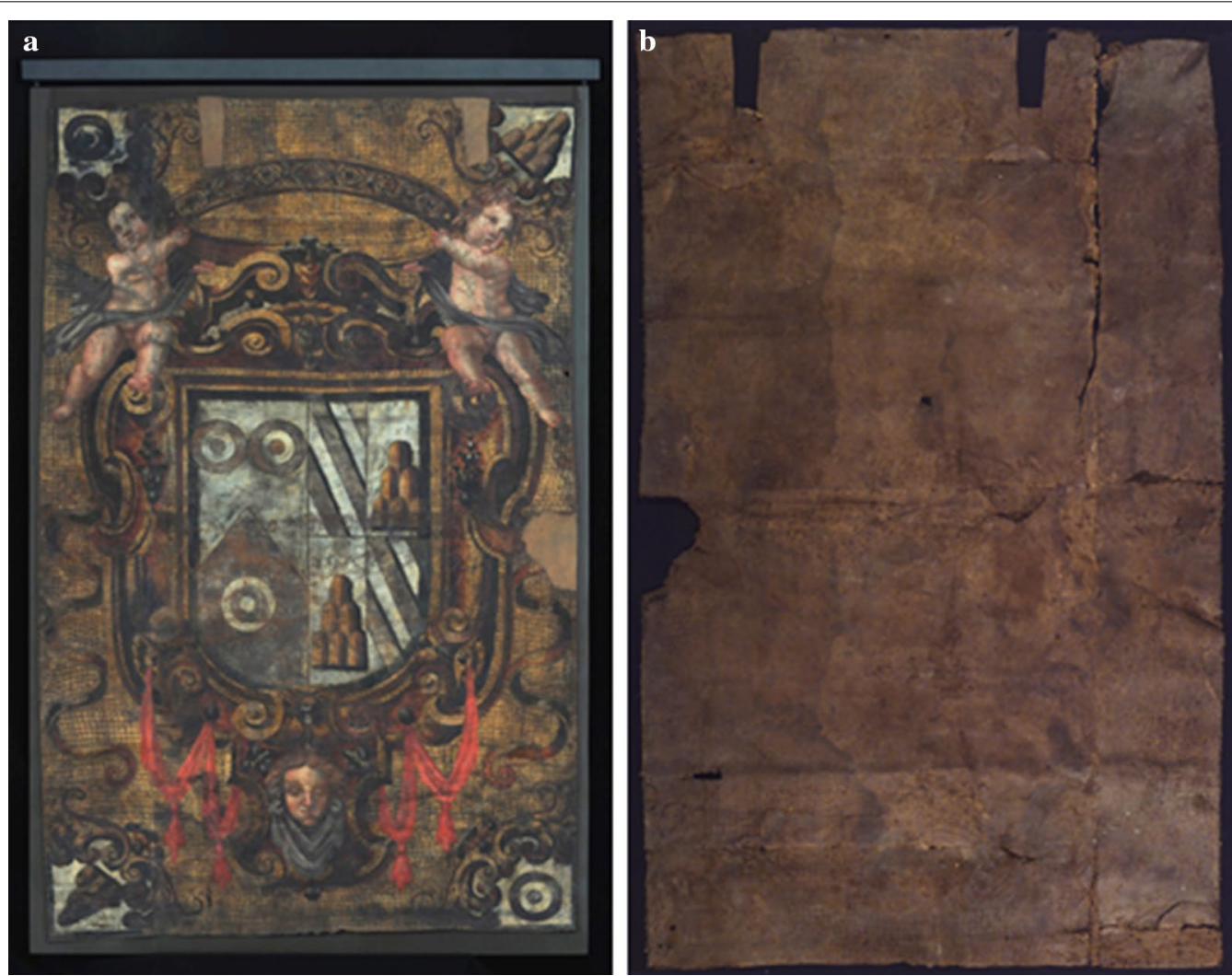

Fig. 2 The "Portiera Oddi-Montesperelli". a Frontal view, b rear view 

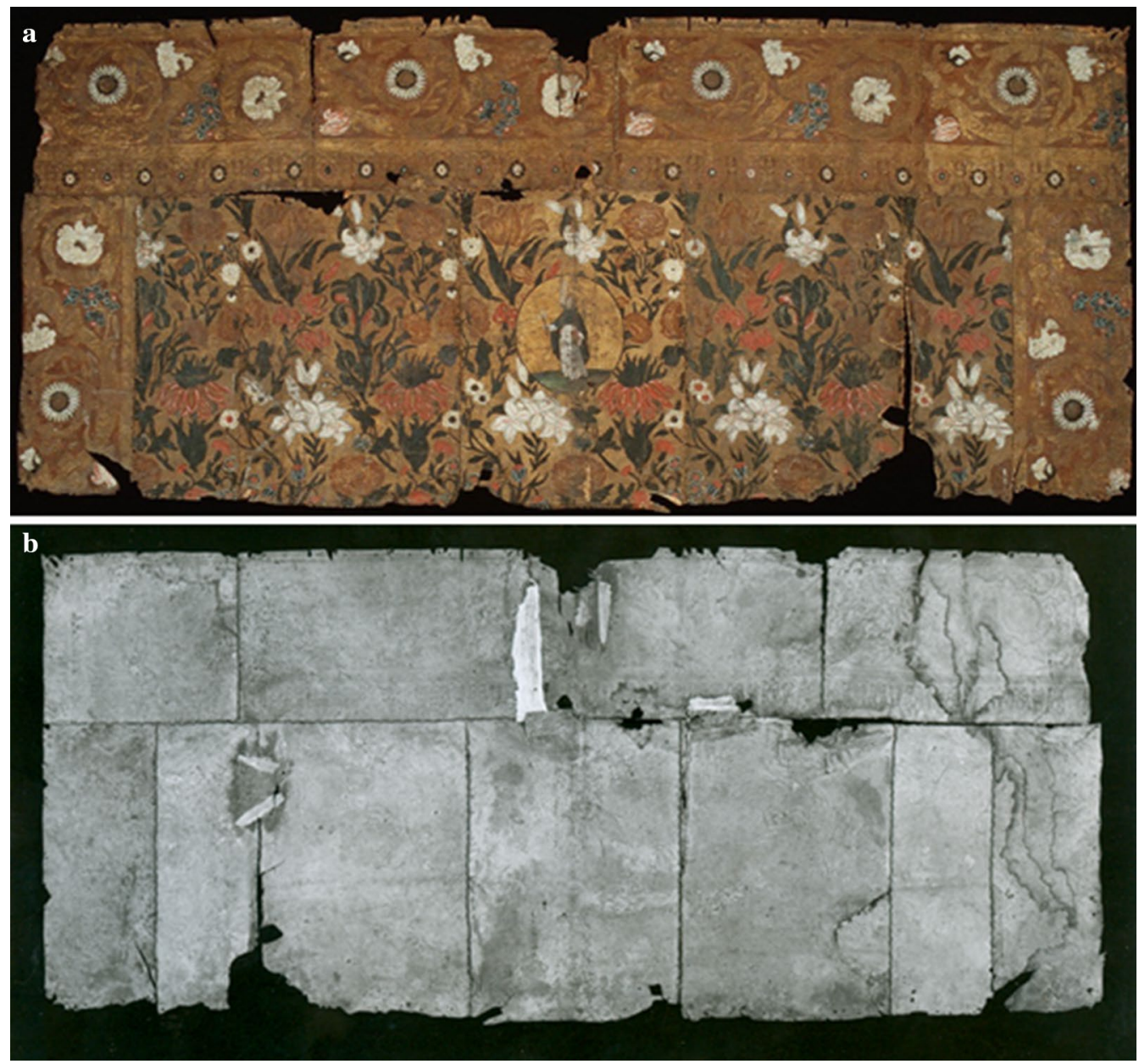

Fig. 3 The "Paliotto di San Domenico": a frontal view, b rear view

positioning. The system was assembled using an industrial mounting system (Montech, Quickset series) characterized of high flexional rigidity and low perpendicularity tolerance. An industrial pc (National Instruments, PXI8105 ) equipped with a 16 bit DAQ acquisition device, and with an custom LabVIEW application (NI, US), triggered the motors and acquired signals. In order to prevent any possible damage, we built the control software to preclude that the laser beam could remain still on the tested artifact for hardware or software bad functioning. Thus, to preserve the integrity of the surface, a disaster recovery procedure was implemented: the measurement heads are automatically moved in a safe location outside the painting and switched off when an alarm code is identified by the in-house developed control software.

The described system was assembled in two different configurations, as a function of the analyzed artwork, as reported below. For both the cases, the test were performed in a controlled microclimate environment.

\section{"Annunciazione"}

The automatic system was used to monitor the horizontal displacements of the canvas fibers during the tensioning tests. The experiments aimed to provide detailed information for the analysis of the residual elasticity of the fibers, so to optimally set the tensioning of the canvas.

As the Fig. 4c shows, two surfaces of the masterpiece were scanned, one area on the front of the painting and one area on back. In the frontal side of the canvas, the full measurement area, $0.275 \times 0.580 \mathrm{~m}^{2}$ (Fig. 4) was divided into two sub-areas of $0.275 \times 0.290 \mathrm{~m}^{2}$ (identified in the figure as areas $\mathrm{A}$ and $\mathrm{B}$ ) due to the robot stroke, which was limited to $0.300 \times 0.300 \mathrm{~m}^{2}$. A reference plane for the canvas deflection at the frontal side was obtained by placing a series of vertical whiteboard tapes, on the supporting frame of the artwork, with a distance of $3 \mathrm{~mm}$ from the canvas. In the posterior area, a surface of $0.275 \times 0.290 \mathrm{~m}^{2}$ (area C) was acquired. Before starting the tests, the parallelism between the painting surface 


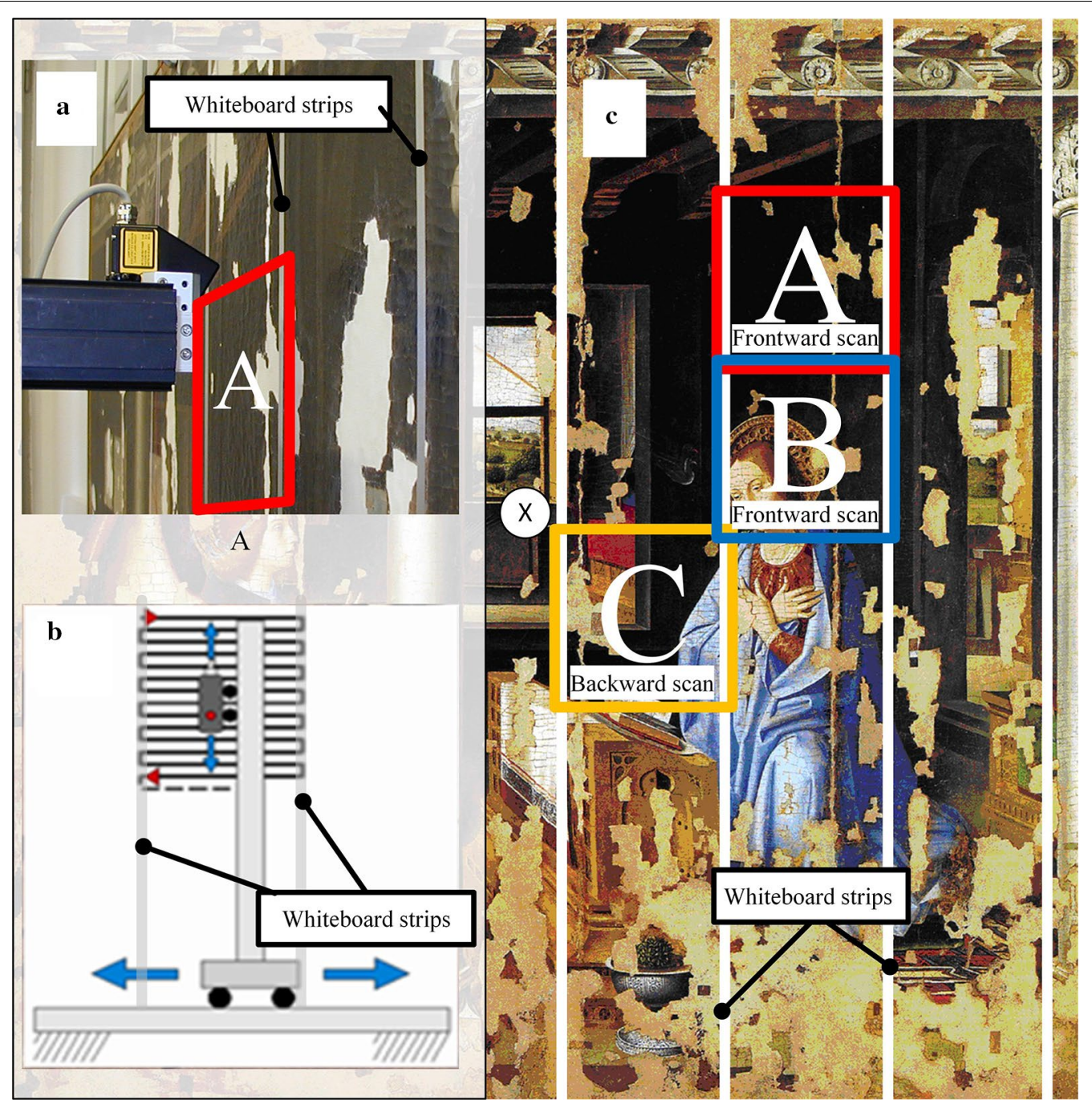

Fig. 4 "Annunciazione": a detail of the laser, ready to scan the frontal area $A$; $\mathbf{b}$ sketch of the trajectory profile of the laser sensor; $\mathbf{c} A$ and $B$ are the scanned frontal areas, $C$ is the posterior one; the vertical lines represent the reference whiteboard strips, fixed to the painting frame; the crossed circle represents the screw position

and the laser's head was controlled by comparing the relative distances at the four corners and at the center of the scanned area. The frame of the mechatronic system was considered to have been correctly positioned when the all the relative distances were less than $0.5 \mathrm{~mm}$. We computed the relative displacement along the orthogonal direction of the canvas, assuming as a reference the plane given by the added whiteboard tapes, for both the frontal and posterior scanned areas.

Figure $4 \mathrm{~b}$ report the laser trajectory performed by the robot end effector: each of the areas A, B and C was divided into a grid of 14 horizontal lines with vertical spacing of $20 \mathrm{~mm}$. In order to limit the vibrations induced by the movement of the robot, the motor speed was limited to $17.00 \pm 0.02 \mathrm{~mm} / \mathrm{s}$. The velocity profile of the robot was trapezoidal, i.e. (1) acceleration, (2) constant speed, and (3) deceleration, but only in (4) the laser output was considered valid.

The acquisitions were conducted in parallel with the verification tests performed by the laboratory staff of the ISCR; the purpose of these tests was to estimate the tensioning level the canvas. The tensioning tests consisted of a micrometer screw, positioned at the center of the rear part of the canvas, used to impose horizontal displacements to the center of the canvas. The actual position of the screw and the correspondent reaction force of the canvas were monitored by a linear variable differential transformer (LVDT) and load cell, respectively (Fig. 5). Because the experiments aimed only to estimate the stress condition of the canvas, the displacement level 


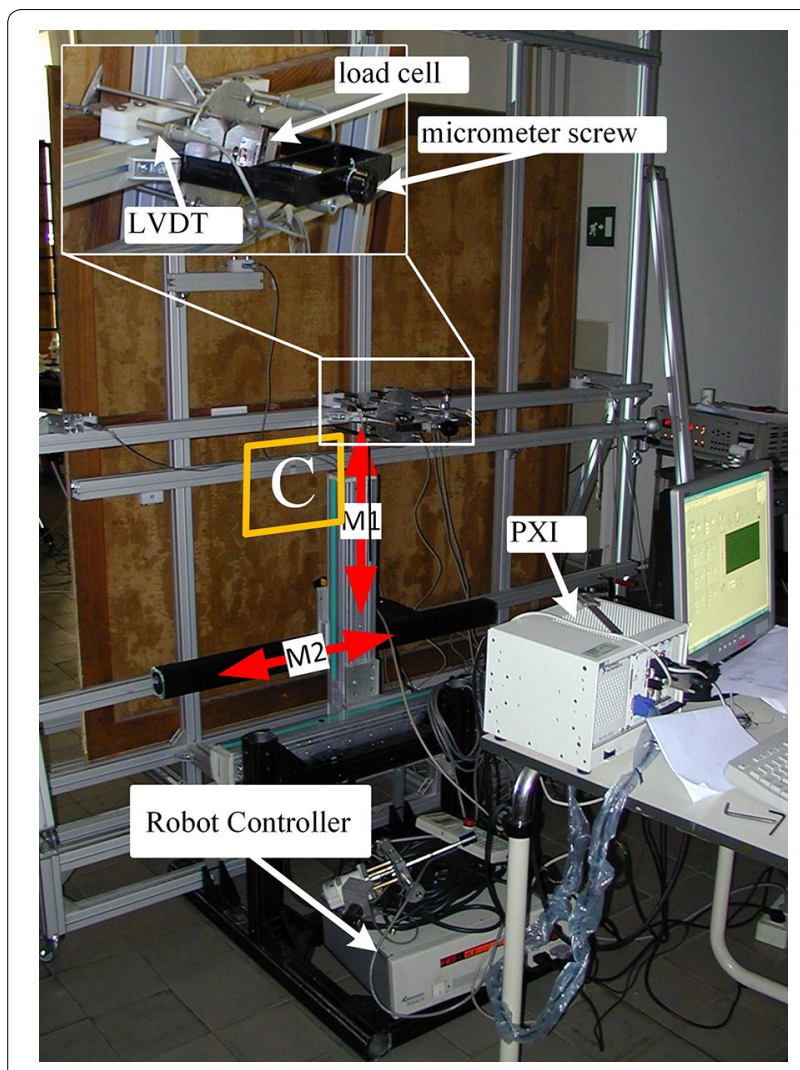

Fig. 5 "Annunciazione": general view of the acquisition system used for scanning the backward area $C$, and of the canvas tensioning hardware

imposed to the center of the canvas was minimal. In addition, any operation have been authorized by the head of the department and the director of the Institute.

Two different tensioning procedures have been implemented. In the first procedure, the micrometer screw advanced with the sequence $(0,1,2) \mathrm{mm}$. In the second procedure, the screw advanced with the sequence $(0$, $3.75,6.25,8.75,10) \mathrm{mm}$. The difference between the two selected ranges was suggested by the team in charge for the restoration. The position of $0 \mathrm{~mm}$ was identified with the simple contact of the screw with the canvas. The laser scan was performed on the areas $\mathrm{A}$ and $\mathrm{B}$, at the front of the canvas, during the first tensioning test, and on the area $\mathrm{C}$, at the back of the canvas, during the second one. The time needed for the acquisition was of about 7 and $4 \mathrm{~m}$ for the two tests, respectively.

The experimental procedure was articulated in: (i) the imposition of a selected out-of-plane condition via the micrometer screw; (ii) the collection of LVDT data; and (iii) the starting of the surface scanning and the gathering of laser sensor outputs.

\section{"Portiera Oddi-Montesperelli" and "Paliotto di San Domenico"}

The "Portiera Oddi-Montesperelli" was analyzed after the conservation treatments to verify the capability of the new support, manufactured by the ISCR, to follow the canvas deformations due to the change of the environmental conditions, i.e. temperature and $\mathrm{RH}$, that could damage the gilding and the stamps [5]. Actually, the fluctuations of temperature and $\mathrm{RH}$ are considered one of the main factors that contribute to the deterioration of artifacts.

The "Paliotto di San Domenico" was monitored before the conservation to permit the design of a new specific support frame, and to use the collected data for a comparison after the expected conservation treatments.

In both the cases, the system was equipped with a temperature and RH transducer (HMT-310, Vaisala, FI).

The robot configuration was similar to the one adopted for "Annunciazione", but with an additional vertical motor M3, having a stroke of $1200 \mathrm{~mm}$ (Fig. 6). The horizontal motor M2 was not used in the present case. Moreover, because the system had to monitor the vertical displacements of the vertical edges of the canvas, two laser sensors were mounted on a horizontal bar fixed to the end-effector of the robot. Two series of markers were positioned on both sides of the "Portiera Oddi-Montesperelli", but only one series on the left side of the "Paliotto di San Domenico" in Fig. 6a (the right side was too much deteriorated). Each 8 consisted of a small plastic clip with square-section $10 \mathrm{~mm} \times 10 \mathrm{~mm}$ and a length $50 \mathrm{~mm}$. In the case of "Paliotto", 8 markers was attached to the canvas vertical edges, and one marker (named $\mathrm{F}$ in Fig. 6a, b) was placed on the fixed frame, close to the canvas. The nominal distanced between each marker pair was $100 \mathrm{~mm}$. In the case of "Portiera", the used markers were $9+1$ in total.

The test procedure can be schematized as it follows: (i) the acquisition of the environmental temperature and relative humidity; (ii) the laser signal acquisition to verify the parallelism between the acquisition system and the panel (parallelism dimensional tolerance $\leq 0.5 \mathrm{~mm}$ ); (iii) the acquisition of the laser signal (scanning speed $\sim 17.00 \pm 0.02 \mathrm{~mm} / \mathrm{s}$ ) for detecting the marker edges, in order to measure the relative distances between each pair of contiguous markers.

The relative displacements were evaluated by acquiring the elapsed time between two consecutive detections of markers and multiplying it for the motor speed. We computed the distance-variation of each pair of markers, defined as the difference between the maximum and the minimum relative distance measured during the day. The marker fixed on the support frame was used as 


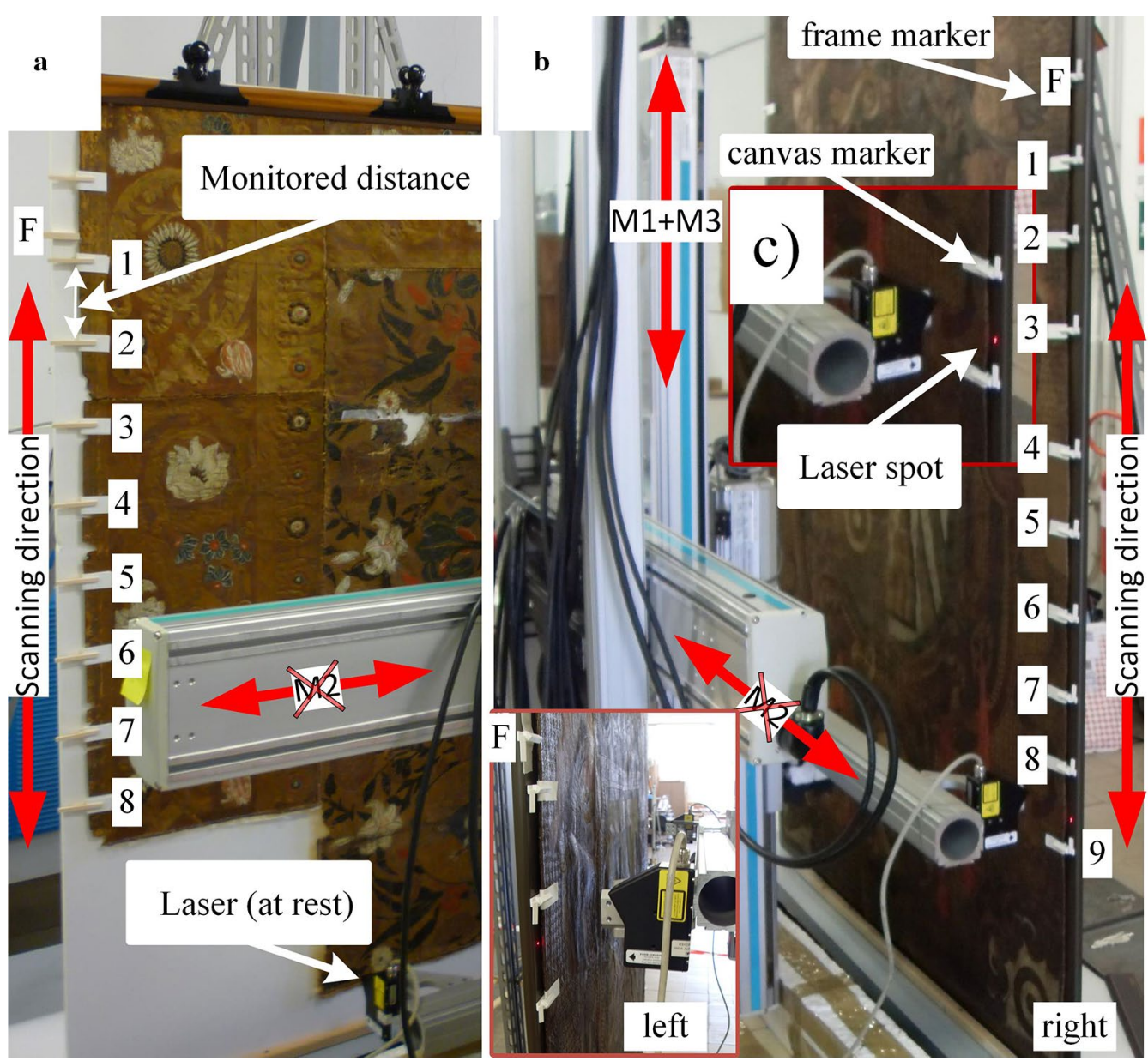

Fig. 6 General view of the acquisition system used for $\mathbf{a}$ the "Paliotto" and $\mathbf{b}$ the "Portiera"; the actuators M1 and M3 were used for positioning the lasers, M2 was not used in this set-up; 8 and 9 markers were fixed on the leather, 1 on the fixed frame; the markers F, attached to the fixed frame, were used as reference for computing the total stretching of the leather

a reference for measuring the total stretching of the two canvases.

The implemented procedure for the monitoring of "Portiera Oddi-Montesperelli" consisted of eight acquisitions from 10:00 a.m. to 4:00 p.m. for three consecutive days. For the "Paliotto di San Domenico", instead, we performed three acquisitions each day, for three nonconsecutive days in the same week, from 12:00 p.m. to 2:00 p.m. For both the cases, the time interval between each acquisition was $40 \mathrm{~min}$. The tests were scheduled automatically in climate-controlled environment.

\section{System characterization}

The uncertainty estimation can be performed (i) by means of repeated measures on a suitable standard reference object (Type-A approach [29]), or, if sufficient and reliable information are available about the relevant error sources, (ii) by a Type-B evaluation approach, or (iii) or by a mixed approach (Type-A plus Type-B).
The use of a reference object is certainly the most reliable method for accuracy estimation of the system. However, the simplicity of the measuring system makes the procedure (ii) sufficiently reliable. The apparatus, in fact, consists of an XY-cartesian robot and a laser displacement sensor, therefore, the only knowledge of the accuracies of both of the devices, certified by the calibrations documents, is basically sufficient to estimate the overall uncertainty value.

The uncertainty has to be estimated differently for both the two configurations previously described, i.e. for the canvas painting and for the leather paintings; however, few preliminary considerations need to be carried out.

The main relevant inaccuracy sources for the overall acquisition system are: (i) the inaccuracy of the robot in reproducing a selected target trajectory; (ii) the uncertainty associated to the laser displacement-sensors; (iii) the precision in assembling the support frame; (iv) the sensitivity of the assembly to environmental effects such 
as temperature and vibrations. The first two sources can be evaluated with Type-B uncertainty estimation approach via the manufacturer specifications. The effects of the third error source could be reduced and estimated by using additional knowledge on the mounting tolerance. In particular, the apparatus mounting inaccuracy, which affects the displacement measures with both systematic and predictable components, can be corrected by using additional geometrical references, acquired during the artwork laser scanning. The assembly sensitivity to temperature and vibrations, instead, cannot be modeled, and, therefore, this phenomenon has to be reduced as much as possible by strengthening the frame and reducing the robot speed at minimum.

\section{"Annunciazione"}

The uncertainty associated to the laser displacement sensor $( \pm 0.005 \mathrm{~mm})$ combines with the planarity tolerance of the robot $( \pm 0.01 \mathrm{~mm})$. Considering independent the two sources of uncertainties, by adding them in quadrature, the uncertainty in the planarity of the scanned surface can be estimated equal to $\pm 0.02 \mathrm{~mm}$. The displacement data were collected while the robot was moving horizontally at a constant sampling $(1 \mathrm{kHz})$, it follows that the capability of the robot to maintain a constant speed influenced the position estimation of the laser within the scan area. In order to reduce the effect of the speed inaccuracy, the external whiteboard tapes have been taken as references for the scanned areas; more precisely, the whiteboard edged has been used to normalize the signals collected for each horizontal line of the scan. The normalization could not eliminate the inaccuracy due to the velocity variation around the average value, but the effect in term of horizontal trajectory inaccuracy is less than the maximum tracking-error admitted by the controller ( $\max$ admitted deviation $\pm 0.05 \mathrm{~mm}$ ). As regards the vertical position of the laser, because it was constant during the scan of each line of the grid, the associated inaccuracy was $0.05 \mathrm{~mm}$, which is negligible in comparison with the horizontal accuracy. In conclusion, the inaccuracy of laser position in the surface scan can be estimated as equal to $0.05 \mathrm{~mm}$.

\section{"Portiera Oddi-Montesperelli" and "Paliotto di San Domenico"}

In these cases the sensors were used only for the detection of the edges of the markers, thus, the accuracy of the laser sensors and the planarity of the robot did not affect the results. The main cause of error can be found in the robot velocity inaccuracy along the vertical direction. Actually, because the aim of the experiment was to monitor only the variation of the vertical relative distances between the markers, and not the absolute displacements, the positional inaccuracy of the robot assumed a minor role. As previously mentioned, the inaccuracy can be considered lower than the tracking error, i.e. $0.05 \mathrm{~mm}$. However, in order to take into account the effect of the temperature on the robot support, an estimation of the robot frame stability had to be performed. Therefore, six markers were attached to a fixed rigid reference frame, simulating a constant marker displacement input for the acquisition system. Two markers were positioned at the higher side of the frame, two at the middle side and two in the lower side. The standard deviation of repeated measures during the daily acquisitions was calculated for the distance between each pair of adjacent markers. The value obtained was $3 \sigma=0.2 \mathrm{~mm}$. In conclusion, the observed deformation of the robot frame during the monitoring can be assumed not greater than $0.2 \mathrm{~mm}$.

\section{Results and discussions "Annunciazione"}

The deformation maps collected at the frontal areas, assuming as a reference the plane identified by the whiteboard tape, are reported in Fig. 7; the results obtained for subareas A and B Fig. 7 are merged in a single figure. A mask of the two areas is superimposed on the Fig. 7a, for sake of clarity. False colors indicate the displacement of the canvas in the normal direction to the reference plane, coincident with the reference tape positioned on the frame.

From an overall analysis of the absolute displacements (Fig. $7 \mathrm{a}-\mathrm{c}$ ) and considering that the micrometer screw is centered at the xy coords $(-275,30)$, it emerges that, as expected, the out-of-plane shape of the canvas increased as the screw position increased. Thus, the experimental method allowed to observe the stretching of the canvas. The dome-shaped profile of the scanned surfaces is perfectly coherent with the displacement of the central point of the canvas imposed by the screw, and, in particular, the position 1 and $2 \mathrm{~mm}$ caused the maximum canvas displacements 0.9 and $1.5 \mathrm{~mm}$, respectively. The procedure of analysis performed for the posterior area gave similar results, as Fig. 8 shows. The dome-shaped profile is again evident, whereas the amplitude of the displacement was greater, because the micrometer screw reached the position of $10 \mathrm{~mm}$.

\section{"Portiera Oddi-Montesperelli"}

As regards the "Portiera Oddi-Montesperelli", the signal acquired in the 3 days were analyzed in order to highlight the distance-variations between the markers on the canvas. The data listed in Table 1 show the distancevariation of the each pair of contiguous markers collected in the three consecutive days. From the table, the 

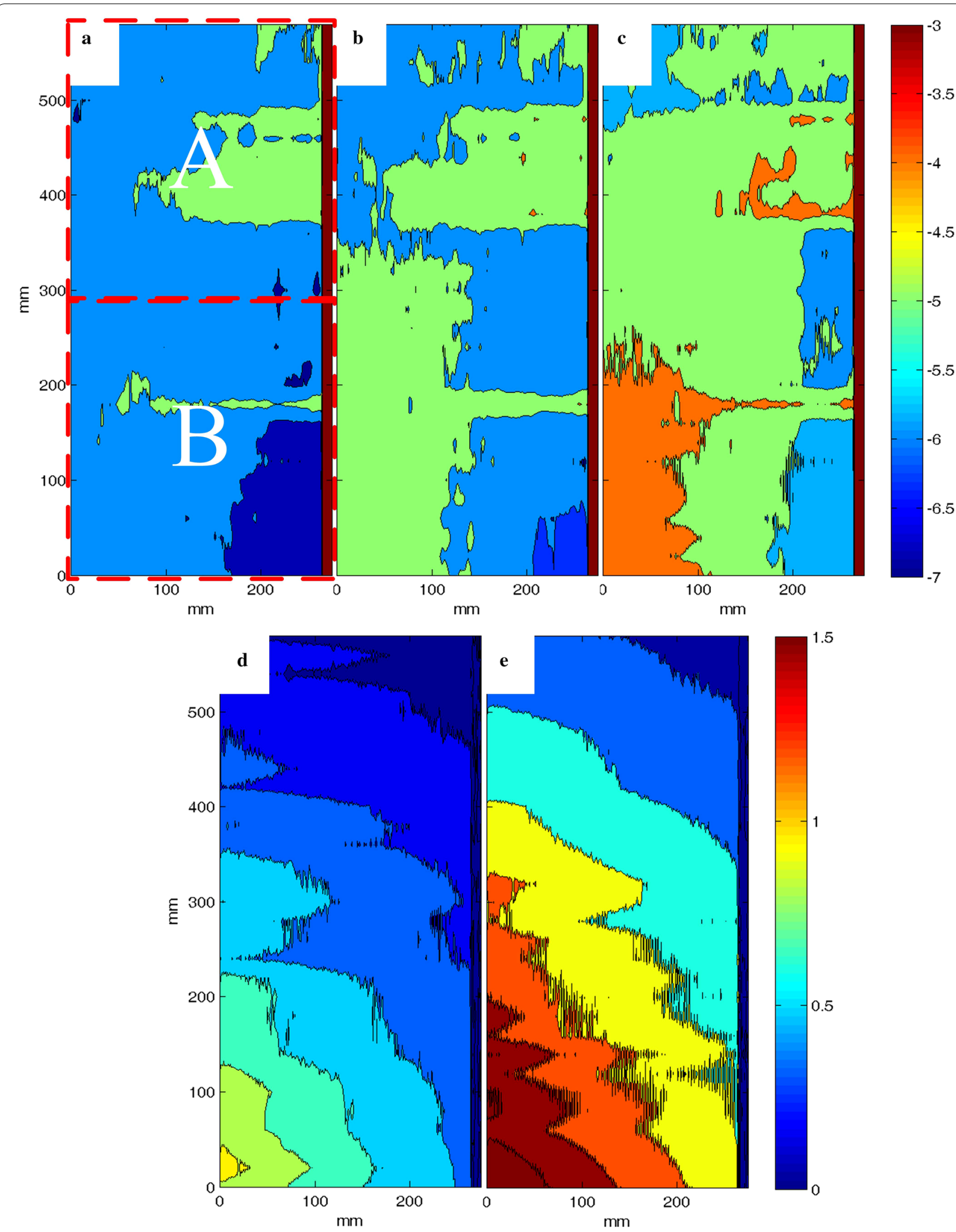

Fig. 7 "Annunciazione", frontward areas $A$ and $B$ : maps of the absolute displacements in correspondence to the screw position equal to $\mathbf{a} 0 \mathrm{~mm}$, $\mathbf{b}$ $1 \mathrm{~mm}, \mathbf{c} 2 \mathrm{~mm}$. Maps of relative (to initial 0 screw position) displacements in correspondence to the screw position equal to $\mathbf{d} 1 \mathrm{~mm}, \mathbf{e} 2 \mathrm{~mm}$. The reference tape is visible on the right side of all the maps $\mathbf{a}, \mathbf{b}, \mathbf{c}$. Colormaps represent the canvas painting displacement in millimeter 

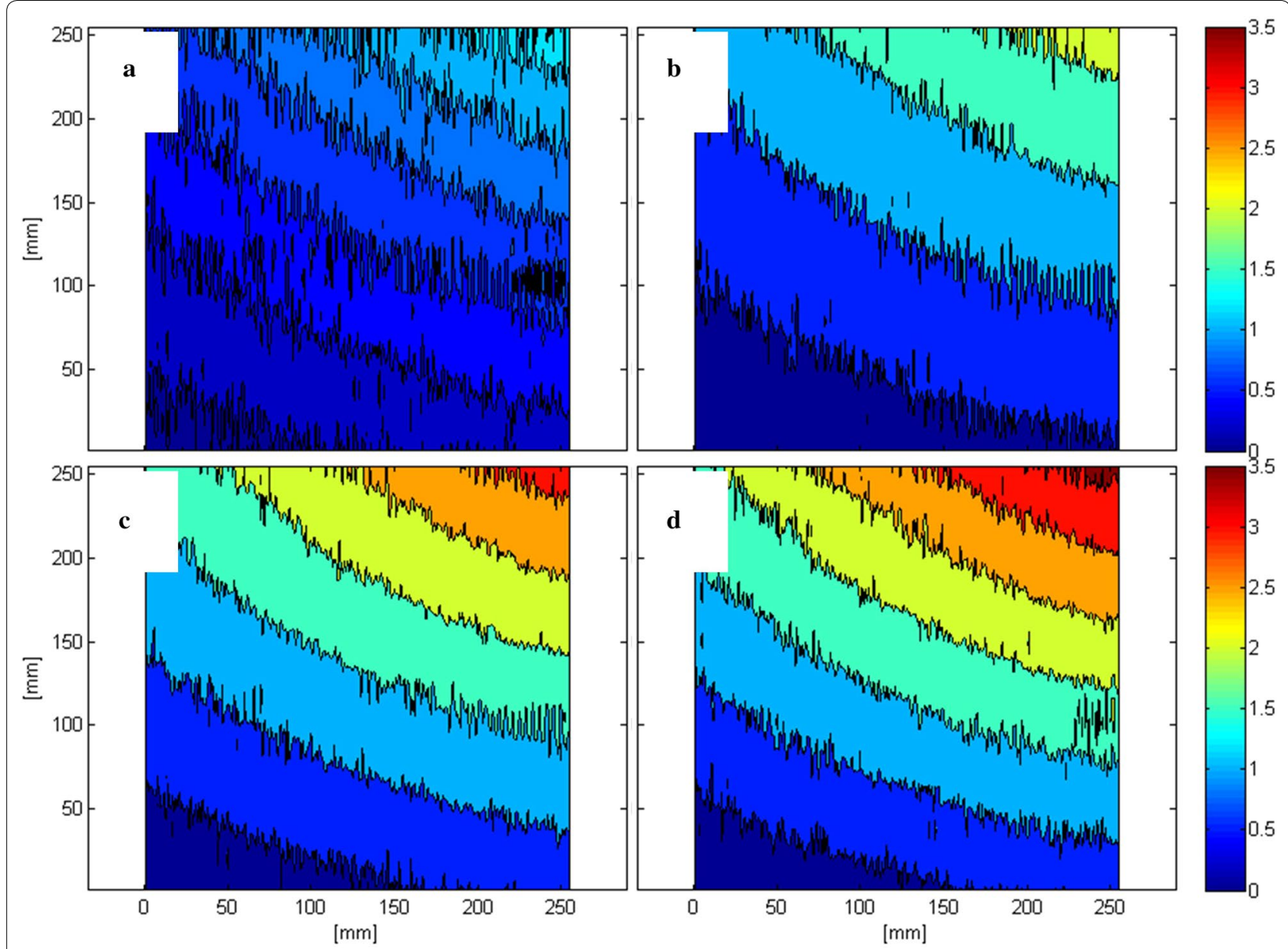

Fig. 8 "Annunciazione", backward area C: maps of relative (to initial $0 \mathrm{~mm}$ screw position) displacements in correspondence to the screw position equal to a $3.75 \mathrm{~mm}$, b $6.25 \mathrm{~mm}, \mathbf{c} 8.75 \mathrm{~mm}$, and $\mathbf{d} 10 \mathrm{~mm}$

Table 1 "Portiera Oddi-Montesperelli": marker distance-variation ( $\pm 0.13 \%)$

\begin{tabular}{|c|c|c|c|c|c|c|c|c|}
\hline \multirow[t]{2}{*}{ Marker pair } & \multicolumn{2}{|l|}{ Day 1} & \multicolumn{2}{|l|}{ Day 2} & \multicolumn{2}{|l|}{ Day 3} & \multicolumn{2}{|l|}{ Mean } \\
\hline & LS (\%) & RS (\%) & LS (\%) & RS (\%) & LS (\%) & RS (\%) & LS (\%) & RS (\%) \\
\hline $1-2$ & 0.40 & 1.07 & 0.93 & 1.40 & 1.07 & 2.20 & 0.80 & 1.53 \\
\hline $2-3$ & 0.93 & 0.80 & 0.67 & 1.40 & 0.67 & 1.07 & 1.07 & 1.07 \\
\hline $3-4$ & 0.40 & 0.80 & 0.93 & 1.07 & 0.93 & 1.60 & 0.80 & 1.20 \\
\hline $4-5$ & 0.67 & 1.07 & 0.80 & 1.07 & 1.07 & 1.93 & 0.87 & 1.40 \\
\hline $5-6$ & 0.67 & 0.80 & 0.53 & 1.40 & 0.53 & 1.93 & 0.60 & 1.40 \\
\hline $6-7$ & 0.53 & 1.67 & 0.67 & 0.80 & 0.67 & 1.40 & 0.67 & 1.27 \\
\hline $7-8$ & 0.80 & 1.07 & 0.93 & 1.07 & 0.80 & 1.93 & 0.87 & 1.40 \\
\hline
\end{tabular}

$L S$ left side, $R S$ right side

non-uniformity of the canvas deformations along the vertical direction is evident. The collected distance-variation ranges, in fact, for the left and right sides, were equal to $(0.4-1.7)$ and $(0.8-2.2) \%$, respectively. Averaging the distance-variations data among the markers, for each side, we obtain the bar diagram reported in Fig. 9a. The trend of the mean distance-variation confirms that the left side was globally less stretched than the right one; in addition, the canvas stretch seemed to increase slightly along the days. The difference between the left and right sides, 

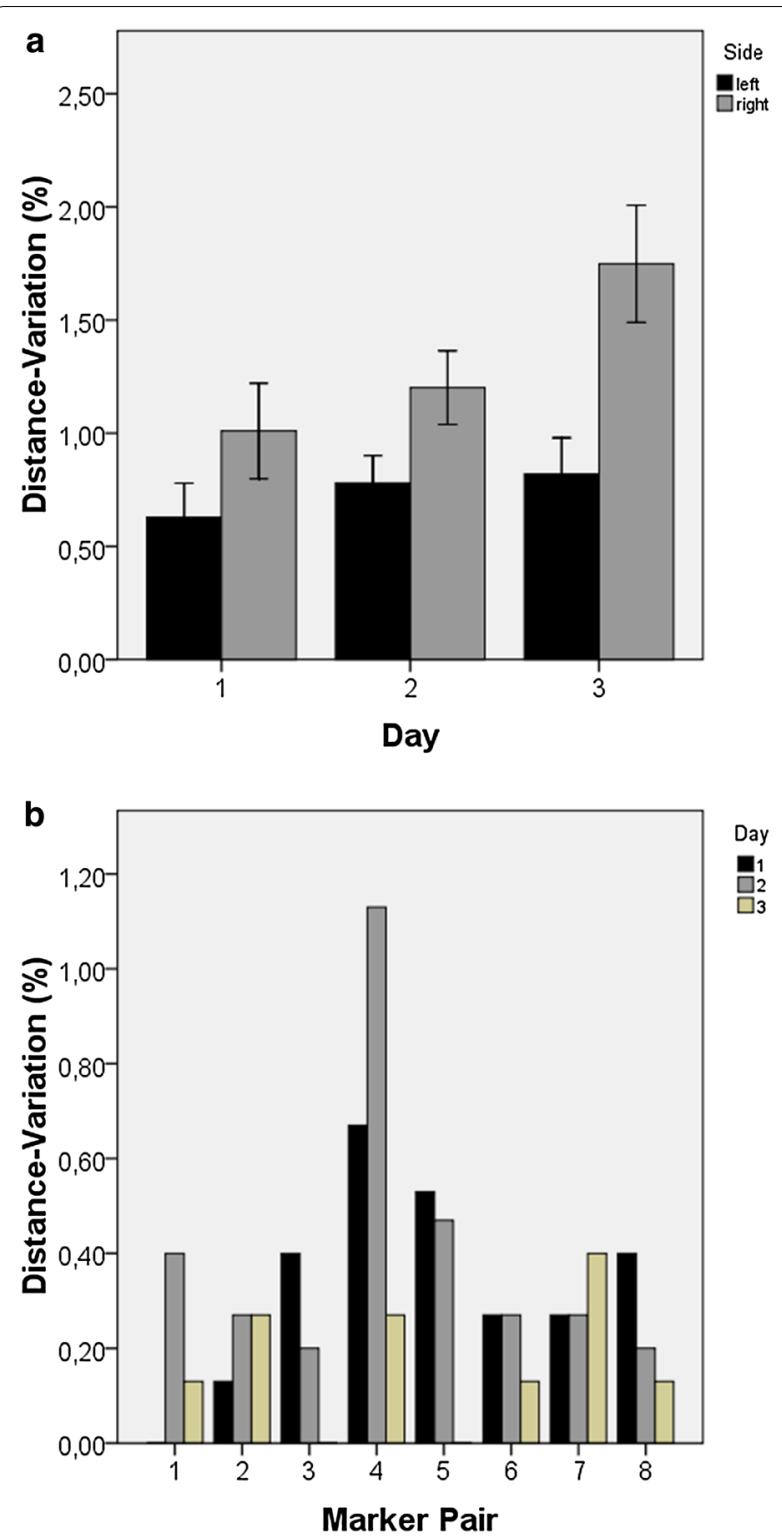

Fig. 9 Marker distance-variation $( \pm 0.13 \%)$ as a function of $\mathbf{a}$ the day and side for the "Portiera Oddi-Montesperelli"; $\mathbf{b}$ the day and the marker for the "Paliotto di San Domenico"

considering all the measurements, was $(1.0 \pm 0.13) \%$. The differences appeared not relevant to produce damage phenomena on the artwork, and they indicated the good performance of the proposed frame in compensating the dimensional changes induced by microclimate variations. The low distance-variations values were due to the small HR changes, equal to (45-50)\%, whereas the temperature of the environment was almost stable, around the value of $21.7 \pm 0.15{ }^{\circ} \mathrm{C}$. The difference among the distancesvariations between each pair of markers, instead, could be addressed to the residual deformation of the canvas, inherited from nighttime HR changes, which reached the peak value of $60 \%$.

\section{"Paliotto di San Domenico"}

The marker distance-variations obtained for the "Paliotto di San Domenico" are itemized in Table 2. From a comparative exam of Table 1 with Table 2, it clearly emerges the range of the measured values in the two artifacts. Actually, lower distance-variations were collected in "Paliotto di San Domenico" than in the "Portiera Oddi-Montesperelli". The reason can be ascribed to the effects of the treatment of restoration that improved the elastic behavior of the Portiera. Regarding the microclimate monitoring, the HR variation was similar to the ones occurred for the "Portiera".

The higher value of the distance-variations between the markers 4 and 5, highlighted in the diagram of the daily mean distance-variation in Fig. 9b, could be addressed to a defect of restoration in the canvas; the presence of the defect probably amplified effects of the microclimate changes.

\section{Conclusions}

In the present paper, a scalable motorized scanning system for canvas paintings was described and tested on three historical artifacts. The design of the apparatus is simple, a Cartesian robot and one or two single-point triangulation lasers. This architecture permitted to estimate the surface scanning accuracy, $\pm 0.05 \mathrm{~mm}$. From the collected data it was possible to assess the multifunctional potential of the here proposed measurement system, that allowed to periodically survey and document the artifact surface shape. These characteristics implies the opportunity to perform test on paintings directly in the exposition environment, with the possibility of an automated monitoring. The deformation maps, acquired during the tensioning tests of the "Annunciazione", showed a canvas deformation, in terms of shape and amplitude, coherent with the screw positions imposed during the experiments. A deeper analysis of the shape of the deformation maps, such as the maximum amplitude and the curvature, could be useful to validate models capable to predict the tensioning level of a canvas painting under a generic load. The analysis on the "Portiera Oddi-Montesperelli" and "Paliotto di San Domenico" have been useful to estimate the capability of the canvas support to follow the length variation of the leather as a function of the environmental conditions. The maximum observed stretching of the two canvases were equal to $(2.2 \pm 0.13) \%$ : this information may be useful to decide if the support frame can be used without causing damage to the masterpiece during the exposition phase in the museum environment. Thus, we can conclude that the proposed systems can 
Table 2 "Paliotto di San Domenico": marker distance-variation $( \pm 0.13 \%)$

\begin{tabular}{lllll}
\hline Marker pair & Day 1 (\%) & Day 2 (\%) & Day 3 (\%) & Mean (\%) \\
\hline $1-2$ & 0.00 & 0.40 & 0.13 & 0.20 \\
$2-3$ & 0.13 & 0.27 & 0.27 & 0.20 \\
$3-4$ & 0.40 & 0.20 & 0.00 & 0.20 \\
$4-5$ & 0.67 & 1.00 & 0.27 & 0.67 \\
$5-6$ & 0.53 & 0.47 & 0.00 & 0.33 \\
$6-7$ & 0.27 & 0.27 & 0.13 & 0.20 \\
$7-8$ & 0.27 & 0.27 & 0.40 & 0.33 \\
$8-9$ & 0.40 & 0.20 & 0.13 & 0.20 \\
\hline
\end{tabular}

support conservators in preventive conservation, which potentially avoids serious damage and the consequent expensive and time-consuming conservation work.

\section{Authors' contributions}

All the authors contributed to the experimental design. FDS and PC wrote the paper, the other authors contributed to review the manuscript. FP and FDS developed the control setup, SR and FDS analyzed the data. All authors read and approved the final manuscript.

\section{Author details}

${ }^{1}$ Department of Mechanical and Aerospace Engineering, DIMA, Sapienza University of Roma, via Eudossiana, Rome, Italy. ${ }^{2}$ Niccolò Cusano University, via Don Gnocchi, Rome, Italy. ${ }^{3}$ DEIM, Tuscia University, largo dell'Università, Viterbo, Italy. ${ }^{4}$ ISCR, MiBACT, via di San Michele, Rome, Italy.

\section{Acknowledgements}

Authors would like to thank Maria Bianca Paris and Anna Valeria Jervis for their help in the studies conducted on the "Paliotto di S. Domenico" and the "Portiera Oddi-Montesperelli".

\section{Competing interests}

The authors declare that they have no competing interests.

\section{Publisher's Note}

Springer Nature remains neutral with regard to jurisdictional claims in published maps and institutional affiliations.

Received: 9 June 2016 Accepted: 12 April 2017

Published online: 02 June 2017

\section{References}

1. Lazaridis M, Katsivela E, Kopanakis I, Raisi L, Panagiaris G. Indoor/outdoor particulate matter concentrations and microbial load in cultural heritage collections. Herit Sci. 2015;3(1):1-13.

2. Berger GA, Russell WH. An evaluation of the preparation of canvas paintings using stress measurements. Stud Conserv. 1988;33(4):187-204.

3. Drago F, Chiba N. Painting canvas synthesis. Vis Comput. 2004;20(5):314-28.

4. Berger GA, Russell WH. Interaction between canvas and paint film in response to environmental changes. Stud Conserv. 1994;39(2):73-86.

5. Hedley G. Relative humidity and the stress/strain response of canvas paintings: uniaxial measurements of naturally aged samples. Stud Conserv. 1988;33(3):133-48.

6. Broggiato G, Campana F, Campanelli F, Cortese L, Santucci G, Torre M. Analisi del tensionamento del dipinto. Caravaggio. La resurrezione di Lazzaro; 2012. p. 92-3.
7. Karpowicz A. A study on development of cracks on paintings. J Am Inst Conserv. 1990;29(2):169-80.

8. Tornari V, Zafiropulos V, Bonarou A, Vainos NA, Fotakis C. Modern technology in artwork conservation: a laser-based approach for process control and evaluation. Opt Lasers Eng. 2000;34(4):309-26.

9. Salimbeni R. Laser techniques for conservation of artworks. Archeometriai Mühely. 2006:3(1):34-40.

10. Young C. Measurement of the biaxial properties of nineteenth century canvas primings using electronic speckle pattern interferometry. Opt Lasers Eng. 1999;31(2):163-70.

11. Robles AA, Sil JL, Claes P, Ortega MD, Rojas MA. Non-destructive in situ spectroscopic analysis of greenstone objects from royal burial offerings of the Mayan site of Palenque, Mexico. Herit Sci. 2015;3:20.

12. Willneff EA, Schroeder SLM, Ormsby BA. Spectroscopic techniques and the conservation of artists' acrylic emulsion paints. Herit Sci. 2014;2(1):25.

13. Groves RM, Pradarutti B, Kouloumpi E, Osten W, Notni G. 2D and 3D nondestructive evaluation of a wooden panel painting using shearography and terahertz imaging. Ndt E Int. 2009:42(6):543-9.

14. Legrand S, Vanmeert F, Van der Snickt G, Alfeld M, De NolfW, Dik J, Janssens K. Examination of historical paintings by state-of-the-art hyperspectral imaging methods: from scanning infra-red spectroscopy to computed X-ray laminography. Herit Sci. 2014;2(1):13.

15. Elkhuizen WS, Zaman T, Verhofstad W, Jonker PP, Dik J, Geraedts JMP. Topographical scanning and reproduction of near-planar surfaces of paintings. In: IS\&T/SPIE electronic imaging. 2014. p. 901809.

16. Zaman T, Jonker P, Lenseigne B, Dik J. Simultaneous capture of the color and topography of paintings using fringe encoded stereo vision. Herit Sci. 2014;2(1):1-10.

17. Karaszewski M, Lech K, Bunsch E, Sitnik R. In the pursuit of perfect 3D digitization of surfaces of paintings: geometry and color optimization. In: Digital heritage. progress in cultural heritage: documentation, preservation, and protection. Berlin: Springer; 2014. p. 25-34.

18. Factum Arte. New developments: Factum Arte's Lucida scanner [Online] Madrid, Spain. 2013. http://www.factum-arte.com/pag/5/Laser-scanning.

19. Lahanier C, Aitken G, Pillay R, Beraldin J-A, Blais F, Borgeat L, Cournoyer L, Picard M, Rioux M, Taylor J. Two-dimensional multi-spectral digitization and three-dimensional modelling of easel paintings. In: Two-dimensional multi-spectral digit three-dimensional model easel paint, vol. 1. 2008.

20. Blais F, Cournoyer L, Beraldin J-A, Picard M. 3D imaging from theory to practice: the Mona Lisa story. In: Optical engineering + applications. 2008. p. 70600L

21. Blais F, Taylor J, Cournoyer L, Picard M, Borgeat L, Dicaire LG, Rioux M, Beraldin JA, Godin G, Lahanier C. Ultra-high resolution imaging at 50 xm using a portable XYZ-RGB color laser scanner. In: Recording, modeling and visualization of cultural heritage: proceedings of the international workshop, Centro Stefano Franscini, Monte Verita, Ascona, Switzerland, May 22-27, 2005. 2005. p. 101

22. Abate D, Menna F, Remondino F, Gattari MG. 3D painting documentation: evaluation of conservation conditions with 3D imaging and ranging techniques. Int Arch Photogramm Remote Sens Spat Inf Sci. 2014;40(5):1.

23. Akça D, Grün A, Breuckmann B, Lahanier C. High definition 3D-scanning of arts objects and paintings. In: Optical 3-D measurement technqiues VIII, vol. II. Zurich, Switzerland: Institute of Geodesy and Photogrammetry, ETH Zurich; 2007. p. 50-8

24. Pezzati L, Fontana R. 3D scanning of artworks. In: C. Office, editor. Handbook on the use of laser in conservation and conservation science. 2008.

25. Blais F. Review of 20 years of range sensor development. J Electron Imaging. 2004;13(1):231-43.

26. Sansoni G, Trebeschi M, Docchio F. State-of-the-art and applications of $3 \mathrm{D}$ imaging sensors in industry, cultural heritage, medicine, and criminal investigation. Sensors. 2009;9(1):568-601.

27. Bunsch E, Sitnik R, Michonski J. Art documentation quality in function of 3D scanning resolution and precision. In: IS\&T/SPIE electronic imaging. 2011. p. 78690D.

28. Ji Z, Leu M-C. Design of optical triangulation devices. Opt Laser Technol. 1989:21(5):339-41.

29. Persson CG. GUM - guide to the expression of uncertainty in measurement. 